
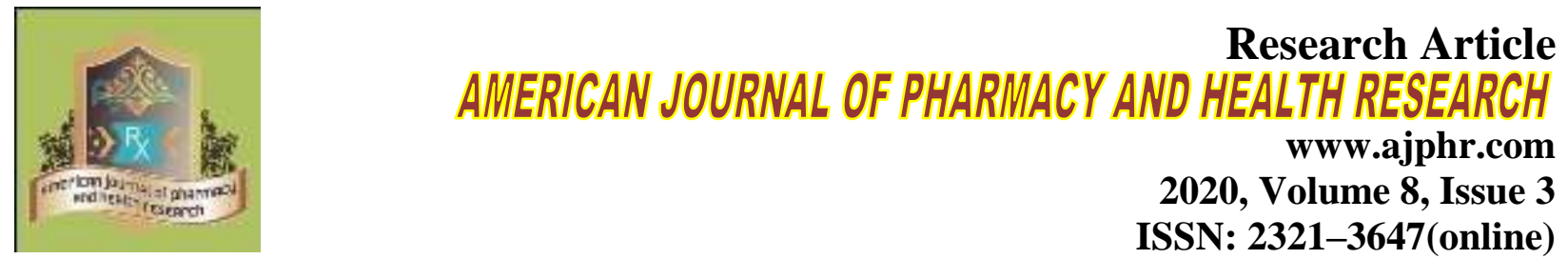

2020, Volume 8, Issue 3

ISSN: 2321-3647(online)

\title{
Design and Characterization of Colon Specific Matrix tablet of a NSAID by Using Various Polymers.
}

\author{
K.S. Srilatha ${ }^{1 *}$, Senthilkumar. K ${ }^{2}$, Akhila Lakshmi.N, ${ }^{1}$ Krishna Manmhon Sah ${ }^{1}$ \\ 1.Department of Pharmaceutics, RR college of Pharmacy Bangalore 560090. \\ 2.Department of Pharmaceutics, Sri Adichunchanagiri college of Pharmacy, Adichunchangiri \\ University, B G Nagar 571448.
}

\begin{abstract}
This short communication reports the pharmacokinetic differences of the glucuronide-conjugated metabolites of magnoflorine and jatrorrhizine between Chinese and African male volunteers. From an earlier report, glucuronidation was determined to be one of the main metabolic pathways and these two compounds were reported to differ significantly between the two races. Pharmacokinetic parameters of half-life, $\mathrm{t}_{1 / 2}$, time to reach maximum concentration, $\mathrm{T}_{\max }$, maximum plasma concentration, $\mathrm{C}_{\max }$, volume of distribution, $\mathrm{Vd}$, area under the concentrationtime curve, AUC and clearance, CL were considered. Statistically significant differences were observed in almost all the parameters studied in terms of their glucuronide-conjugated metabolites. The findings indicate the differences in hepatic metabolism of these two compounds between the two races.
\end{abstract}

Keywords: conjugate, glucuronide, metabolite, pharmacokinetics, races. 


\section{INTRODUCTION}

Goal of designing sustained release formulation is to achieve better selectivity and longer duration of action with possible minimal dose, dosing frequency, side effects and improve patient convenience. The most commonly used method of modulating the drug release is to include it in a matrix system. Colon specific drug delivery should be capable of releasing bioactive agent into the colon i.e. Drug release and absorption should not occur in the stomach as well as the intestine, and the bioactive agent should be not degraded in either of the dissolution sites but only released and absorbed once reaches the colon which has a long residence time of $72 \mathrm{hrs}$ with high water content that favors absorption of poorly absorbed drug and improves bioavailability.

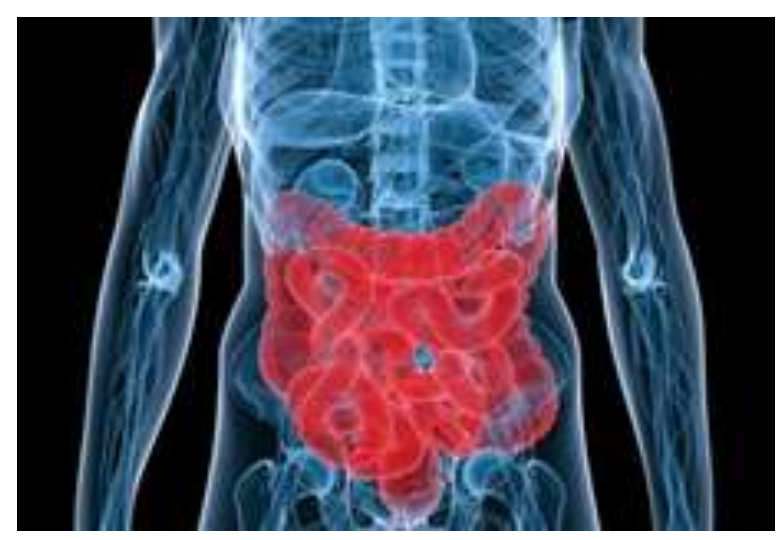

Figure 1: Diagrammatic representation of colon.

Oral delivery of drug to the colon is valuable in the treatment of diseases of colon such as colon cancer ,ulcerative colitis, crohn's diseases and inflammatory bowel diseases whereby high local concentration can be achieved while minimizing side effects and also used in treatment of asthma, angina and rheumatoid arthritis and delivery of steroids. 


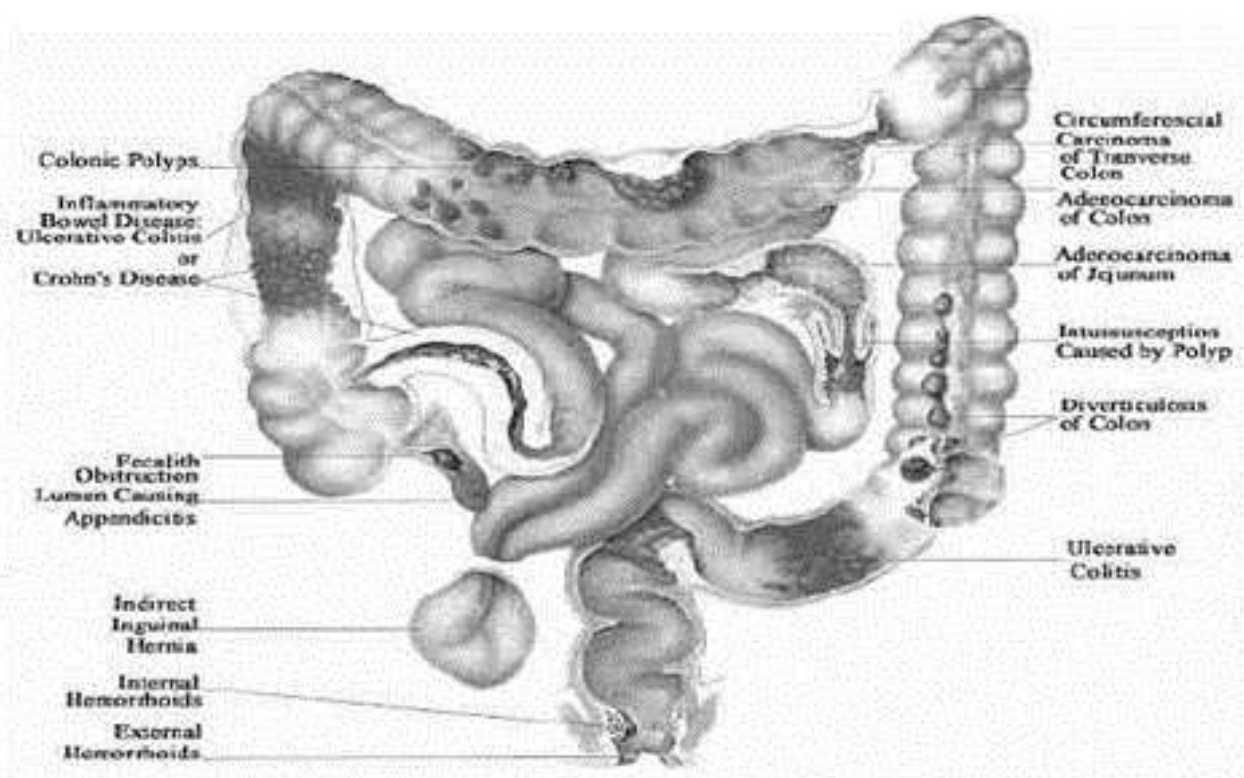

Figure 2: diagrammatic representation of colon associated disease.

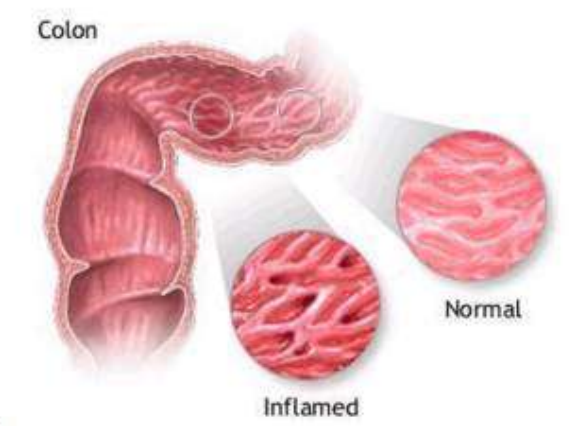

Figure 3: Presentation of inflamed and normal colon

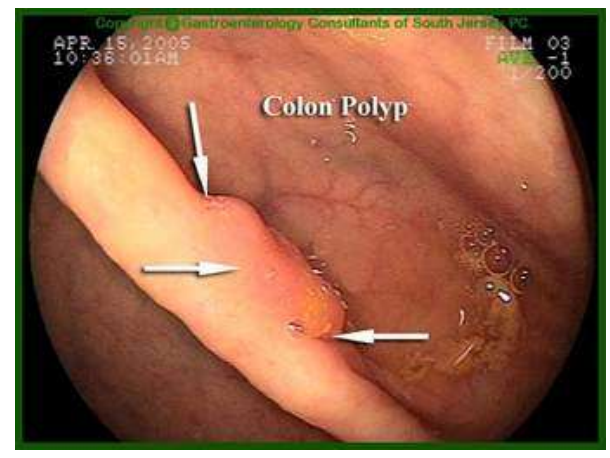

Figure 4: Diagrammatic presentation of inflamed colon

\section{Matrix tablet}

Matrix tablet is defined as oral solid dosage form in which the active ingredient is homogeneously dispersed throughout the hydrophilic and hydrophobic matrix which serve as release rate retardants procedure such as coating and pelletization during manufacturing and drug release rate from the dosage form is controlled mainly by the type and proportion of polymer used in formulation. It plays as an important tool in for oral controlled release dosage 
forms. Problems like patient compliance, drug targeting, local side effect frequent administration and fluctuation in blood concentration level, associated with their counterparts, the conventional dosage forms were rectified.

\section{Ketoprofen}

Ketoprofen is a propionic acid derivative drug belonging to the group of nonsteroidal antiinflammatory drugs (NSAIDs) used as anti-inflammatory and analgesic for the treatment of rheumatoid arthritis, osteoarthritis and in reduction of fever and inflammation thus also used in treatment of colon cancer ,ulcerative colitis, crohn's diseases and inflammatory bowel diseases.

\section{Sustained release matrix tablet}

Sustained release dosage forms are designed to complement the pharmaceutical activity of the medicament in order to achieve better selectivity and longer duration of action. Sustained release preparations are helpful to reduce the dosage and improve patients convenience. Sustained release are easy to fabricate by incorporating drug molecules in slowly disintegrating or inert porous materials. The most commonly used method of modulating the drug release is to include it in a matrix system.

\section{MATERIALS AND METHODS}

Ketoprofen was obtained from Yarrow chem products Mumbai, Ethyl cellulose talc and Lactose was obtained from Fine chem limited Mumbai, xanthan gum and guar gum was obtained from Balaji drugs, Bangalore. Chitosan was obtained from Himedia llaboratories Mumbai and magnesium stearate was obtained from Thomas Baker Pvt Ltd, Mumbai.

\section{1)Standard stock solution of Ketoprofen}

$10 \mathrm{mg}$ of ketoprofen was taken and diluted with $100 \mathrm{ml}$ of phosphate buffer $(100 \mu \mathrm{g} / \mathrm{ml})$. From that solution $1,2,3,4,5 \mathrm{ml}$ taken in different volumetric flask was diluted with $\mathrm{pH} 7.4$ phosphate buffer to give $10,20,30,40,50 \mu \mathrm{g} / \mathrm{ml}$. The absorption of solutions was measured at $260 \mathrm{~nm}$.

\section{FORMULATON OF MATRIX TABLET OF KETOPROFEN}

\section{2)Method of preparation sustained release matrix tablets:}

Ketoprofen was added with three different types of natural polymer like(xanthan gum, guar gum and chitosan) and one grade of ethyl cellulose ether derivative in several drug to polymer ratio lactose ,talc and magnesium stearate was also added as diluent, glidant and lubricant and mixed properly in motor and pestle for about 15 minutes and compressed into tablets by using direct compression method and examined for their physical properties and appearance . 
Table 1: Formulations of matrix tablet of Ketoprofen

\begin{tabular}{llllllllllllll}
\hline SI no. & Ingredients & F1 & F2 & F3 & F4 & F5 & F6 & F7 & F8 & F9 & F10 & F11 & F12 \\
\hline 1 & Ketoprofen & 200 & 200 & 200 & 200 & 200 & 200 & 200 & 200 & 200 & 200 & 200 & 200 \\
2 & Guar gum & 200 & 300 & 400 & - & - & - & - & - & - & - & - & - \\
3 & Xanthan gum & - & - & - & 200 & 300 & 400 & - & - & - & - & - & - \\
4 & Chitosan & - & - & - & - & - & - & 200 & 300 & 400 & - & - & - \\
5 & Guar gum: & - & - & - & - & - & - & - & - & - & $100: 100$ & $100: 200$ & $100: 300$ \\
& xanthan gum & & & & & & & & & & & & \\
6 & Ethyl cellulose & 100 & 100 & 100 & 100 & 100 & 100 & 100 & 100 & 100 & 100 & 100 & 100 \\
7 & Lactose & 263 & 163 & 63 & 263 & 163 & 63 & 263 & 163 & 63 & 263 & 163 & 63 \\
8 & Mg stearate & 4 & 4 & 4 & 4 & 4 & 4 & 4 & 4 & 4 & 4 & 4 & 4 \\
9 & Talc & 3 & 3 & 3 & 3 & 3 & 3 & 3 & 3 & 3 & 3 & 3 & 3 \\
\hline
\end{tabular}

\section{EVALUATION}

\section{Micrometric properties.}

\section{a) Angle of repose.}

The angle of repose of powder was determined by the fixed funnel method. The accurately weighed powder was taken in a funnel. The powder was allowed to flow through funnel freely onto the surface in such a way that tip of funnel does not touch the heap of powder. The diameter of the powder cone was measured and angle of repose was calculated using the following equation.

$\tan \theta=\mathbf{h} / \mathbf{r}$

\section{b) Bulk density.}

Powder from each formulation, previously lightly shaken to break any agglomerates formed was introduced into a $100 \mathrm{ml}$ measuring cylinder. After the initial volume was observed, the cylinder was allowed to fall under its own weight onto a hard surface from the height of 2.5 $\mathrm{cm}$ at 2 second intervals. The tapping was continued until no further change in volume was noted and calculated by using formulas.

\section{Bulk density = weight of powder / bulk volume of powder \\ Tapped density=weight of powder/tapped volume of powder}

\section{c) Compressibility index and Hausner's ratio.}

The compressibility index has been proposed as an indirect measure of bulk density, size and shape, surface area, moisture content and cohesiveness of materials because all of these can influence the observed compressibility index. The compressibility index and the hausner's ratio are determined by measuring both the bulk volume and the tapped volume of a powder. 


\section{Compressibility Index $(\%)=($ TBD - LBD $) \times 100 /$ TBD}

\section{Hausner's ratio $=T B D / L B D$}

\section{II) Physicochemical parameters:}

\section{a) Tablet hardness}

The resistance of tablet for shipping or breakage, under conditions of storage, transportation and handling, before usage, depends on its hardness. The hardness of tablet of each formulation was measured by using Pfizer hardness tester.

\section{b) Tablet thickness}

Thickness of tablets was important for uniformity of tablet size. Thickness was measured by using screw gauge on 3 randomly selected samples.

c) Friability

Friability is the measure of tablet strength. Roche friabilator was used for testing the friability. Ten tablets were weighed accurately and placed in the plastic chamber that revolves at $25 \mathrm{rpm}$ for 4 min dropping the tablets through a distance of six inches with each revolution. After 100 revolutions, the tablets were re-weighed and the percentage loss in tablet weight was determined.

$\%$ Loss = initial wt. of tablets - final wt. of tablets / initial wt. of tablets $\times 100$

\section{d) Weight variation}

Twenty tablets were weighed individually and the average weight was determined. Then percentage deviation from the average weight was calculated.

\section{e) Uniformity of drug content}

Ten tablets were weighed and average weight is calculated. All tablets were crushed and Powder weight equivalent to $200 \mathrm{mg}$ drug was dissolved in phosphate buffer $\mathrm{pH} 7.4$ and the volume was made up to $10 \mathrm{ml}$ with phosphate buffer $\mathrm{pH} 7.4$ from the stock solution, $1 \mathrm{ml}$ solution was taken in $10 \mathrm{ml}$ volumetric flask and the volume was made with phosphate Buffer $\mathrm{pH} 7.4$ Further $0.1 \mathrm{ml}$ pipetted and made up to $10 \mathrm{ml}$ with phosphate buffer $\mathrm{pH} 7.4$ Solution was filtered and absorbance was measured spectrophotometrically at $260 \mathrm{~nm}$ against phosphate buffer pH 7.4 as a blank. Amount of drug present in one tablet was calculated.

\section{f) Dissolution studies}

The release profile of matrix tablets was determined using USP dissolution testing Apparatus II (paddle type) at $100 \mathrm{rpm}$, employing the round bottom dissolution vessel and rotating paddles basket assembly. The dissolution test was performed using $\mathrm{pH} 1.2$ buffer for two hours and $\mathrm{pH}$ 7.4 buffer for 8 hours. The temperature of the dissolution medium was maintained $37^{\circ} \mathrm{C} \pm 1^{\circ} \mathrm{C}$. 1 
$\mathrm{ml}$ of the sample was withdrawn at regular Intervals and replaced with the same volume of fresh dissolution medium. The withdrawn samples were made up to $10 \mathrm{ml}$ using phosphate buffer $\mathrm{pH}$ 7.4. After filtration, the amount of drug release was determined from the standard calibration curve of pure drug at $260 \mathrm{~nm}$.

\section{g) Drug release kinetic from the sustained release matrix tablet dosage forms}

Drug release from matrices usually implies water penetration in the matrix, hydration, swelling, and diffusion of the dissolved drug. Several kinetics models relating to the drug release from matrices, selected from the most important mathematical models done here. However, it is worth to mention that the release mechanism of a drug would depend on the dosage from selected, $\mathrm{pH}$, nature of the drug and polymer used.

\section{h) Stability studies}

Stability testing of drug products begins as a part of drug discovery and ends with the Demise of the compound or commercial product. The stability studies were carried out of the most satisfactory formulation. The most Satisfactory formulation sealed in aluminum packaging and kept in humidity Chamber maintained at $40 \pm 2{ }^{\circ} \mathrm{C} / 75 \pm 5 \% \mathrm{RH}$ for three months. At the end of studies, samples were analyzed for the drug content and in vitro release studies.

\section{RESULTS AND DISCUSSION}

\section{Drug estimation}

Ketoprofen was found to be soluble in methanol, ethanol, acetone and insoluble in water with a melting point of $94-97^{\circ} \mathrm{C}$ and $260 \mathrm{~nm} \lambda \max$ in UV spectrometry. In standard calibration curve the regression coefficient was found to be 0.9994 in phosphate buffer and 0.9996 in acidic buffer and slope value was 0.011 and 0.114 showed linearity between absorbance and concentration

\section{FT- IR Spectroscopy}

$F T$ - IR studies were carried out for pure Ketoprofen alone and along with polymers such as ethyl cellulose, guar gum, xanthan gum, chitosan and lactose. The spectrums were investigated for any possible interactions between Ketoprofen and polymers used in the formulations which indicated that the purity of ketoprofen was maintained in physical mixture along with polymer without any significant chemical interactions. 


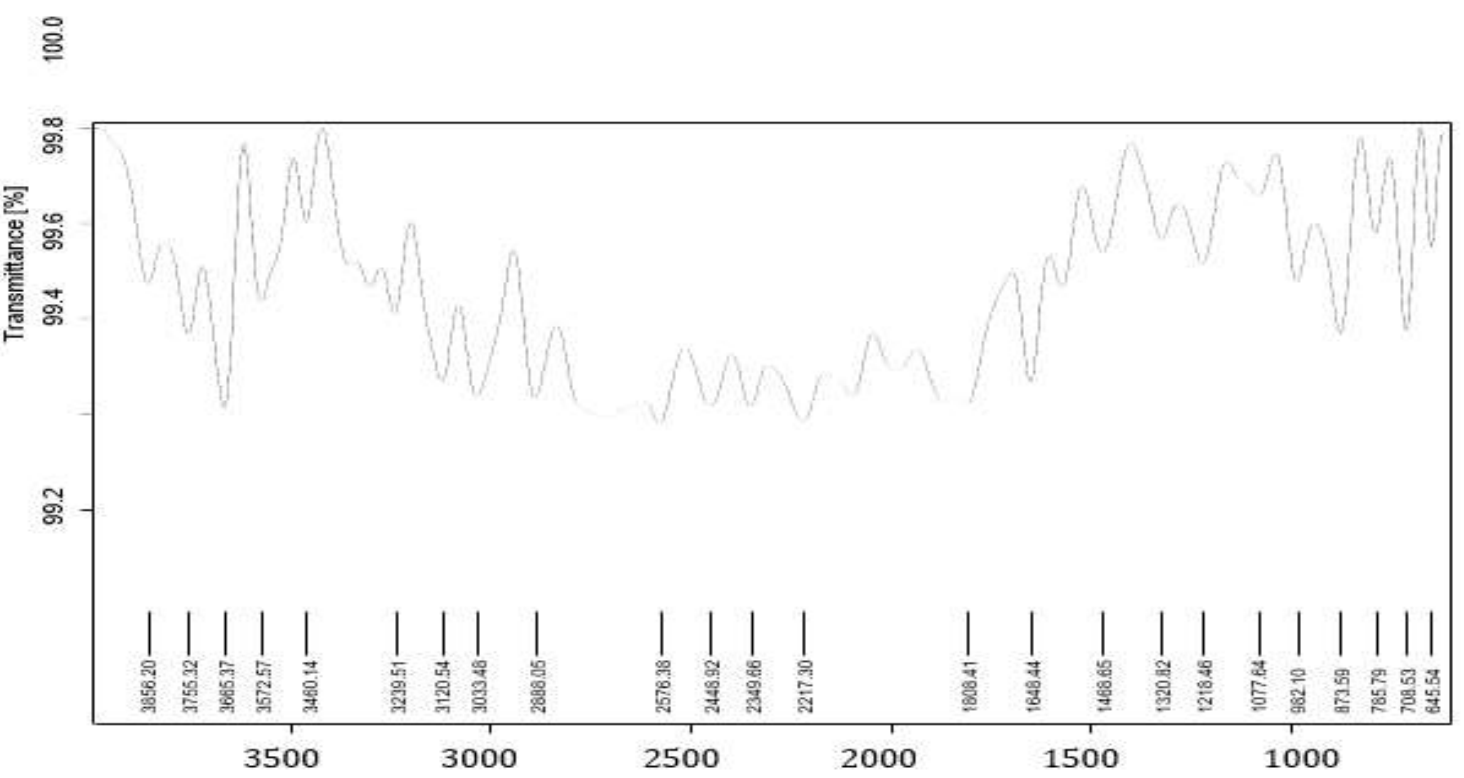

Figure 5: FTIR Spectrum of pure Ketoprofen.

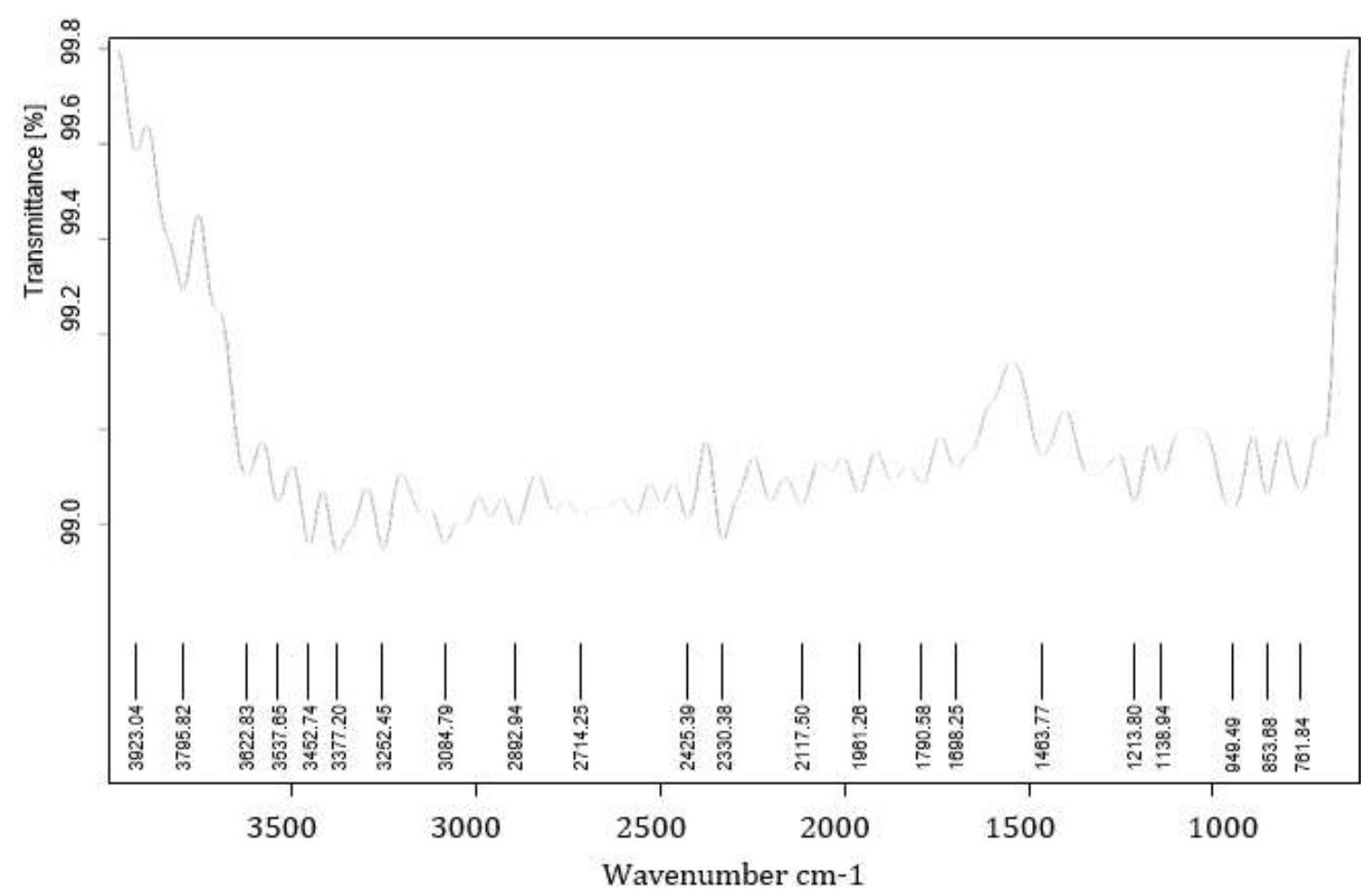

Figure 6: FTIR Spectrum of pure Ketoprofen and excipients.

Table 2: micrometric properties

\begin{tabular}{lllllc}
\hline $\begin{array}{l}\text { Formulation } \\
\text { code }\end{array}$ & $\begin{array}{l}\text { Angle of } \\
\text { repose }\left({ }^{\circ}\right) \pm\end{array}$ & $\begin{array}{l}\text { Bulk } \\
\text { density }(\mathbf{g m} / \mathbf{m l}) \\
\mathbf{\mathbf { S } \text { SD }}\end{array}$ & $\begin{array}{l}\text { Tapped } \\
\text { density }(\mathbf{g m} / \mathbf{m l}) \\
\mathbf{\mathbf { S } S D}\end{array}$ & $\begin{array}{l}\text { Carr's } \\
\text { Index( \%) } \\
\mathbf{\pm S D}\end{array}$ & $\begin{array}{l}\text { Hausner's } \\
\text { ratio } \pm \text { SD }\end{array}$ \\
\hline F1 & $26.54 \pm 0.05$ & $0.56 \pm 0.01$ & $0.64 \pm 0.01$ & $12.5 \pm 0.16$ & $1.14 \pm 0.03$ \\
F2 & $28.42 \pm 0.04$ & $0.55 \pm 0.03$ & $0.66 \pm 0.04$ & $16.66 \pm 0.25$ & $1.2 \pm 0.05$ \\
F3 & $26.89 \pm 0.05$ & $0.54 \pm 0.01$ & $0.65 \pm 0.04$ & $16.92 \pm 1.9$ & $1.2 \pm 0.02$ \\
F4 & $25.98 \pm 0.06$ & $0.54 \pm 0.02$ & $0.64 \pm 0.06$ & $15.62 \pm 0.53$ & $1.18 \pm 0.004$ \\
\hline \hline
\end{tabular}




\begin{tabular}{llllll}
\hline F5 & $27.45 \pm 0.04$ & $0.58 \pm 0.03$ & $0.67 \pm 0.04$ & $13.43 \pm 0.18$ & $1.15 \pm 0.01$ \\
F6 & $25.42 \pm 0.13$ & $0.53 \pm 0.04$ & $0.63 \pm 0.04$ & $15.87 \pm 0.24$ & $1.18 \pm 0.05$ \\
F7 & $30.51 \pm 1.33$ & $0.53 \pm 0.02$ & $0.64 \pm 0.05$ & $17.18 \pm 0.012$ & $1.2 \pm 0.002$ \\
F8 & $28.18 \pm 0.07$ & $0.55 \pm 0.02$ & $0.66 \pm 0.06$ & $16.66 \pm 1.12$ & $1.2 \pm 0.004$ \\
F9 & $25.98 \pm 0.07$ & $0.54 \pm 0.03$ & $0.65 \pm 0.04$ & $16.92 \pm 0.62$ & $1.2 \pm 1.13$ \\
F10 & $31.72 \pm 0.15$ & $0.56 \pm 0.02$ & $0.65 \pm 0.03$ & $13.84 \pm 0.42$ & $1.16 \pm 0.03$ \\
F11 & $28.67 \pm 0.03$ & $0.54 \pm 0.01$ & $0.65 \pm 0.03$ & $16.92 \pm 0.45$ & $1.2 \pm 0.004$ \\
F12 & $27.12 \pm 0.06$ & $0.53 \pm 0.02$ & $0.62 \pm 0.02$ & $14.51 \pm 0.08$ & $1.16 \pm 0.005$ \\
\hline
\end{tabular}

Table: 3. Physicochemical properties

\begin{tabular}{llllll}
\hline $\begin{array}{l}\text { Formulation } \\
\text { code }\end{array}$ & $\begin{array}{l}\text { Thickness } \\
(\mathbf{m m}) \pm \text { SD }\end{array}$ & $\begin{array}{l}\text { Hardness } \\
(\mathbf{k g} / \mathbf{c m}) \pm \text { SD }\end{array}$ & $\begin{array}{l}\text { Friability } \\
(\boldsymbol{\%} \text { loss })\end{array}$ & $\begin{array}{l}\text { Weight } \\
\text { Variation } \\
(\mathbf{m g})\end{array}$ & $\begin{array}{l}\text { Drug content } \\
(\boldsymbol{\%})\end{array}$ \\
\hline F1 & $5.1 \pm 0.2$ & $5.5 \pm 0.05$ & 0.40 & $776.8 \pm 24.74$ & 94.46 \\
F2 & $5.0 \pm 0.2$ & $5.6 \pm 0.03$ & 0.36 & $781.25 \pm 28.45$ & 98.24 \\
F3 & $4.9 \pm 0.1$ & $5.7 \pm 0.13$ & 0.42 & $772.14 \pm 32.25$ & 96.48 \\
F4 & $5.0 \pm 0.1$ & $5.4 \pm 0.22$ & 0.45 & $778.29 \pm 31.23$ & 95.59 \\
F5 & $5.0 \pm 0.2$ & $5.8 \pm 0.12$ & 0.38 & $778.29 \pm 34.29$ & 98.16 \\
F6 & $5.1 \pm 0.1$ & $5.6 \pm 0.005$ & 0.29 & $772.23 \pm 27.24$ & 98.69 \\
F7 & $5.0 \pm 0.2$ & $5.5 \pm 0.5$ & 0.34 & $776.34 \pm 32.23$ & 99.85 \\
F8 & $5.1 \pm 0.1$ & $5.6 \pm 0.04$ & 0.43 & $782 \pm 23.45$ & 96.82 \\
F9 & $5.0 \pm 0.01$ & $5.5 \pm 0.41$ & 0.44 & $774.35 \pm 25.65$ & 93.42 \\
F10 & $5.0 \pm 0.2$ & $5.3 \pm 0.17$ & 0.43 & $779.02 \pm 34.28$ & 96.57 \\
F11 & $5.1 \pm 0.1$ & $5.4 \pm 0.11$ & 0.44 & $781.35 \pm 32.28$ & 95.46 \\
F12 & $5.0 \pm 0.2$ & $5.4 \pm 0.15$ & 0.35 & $775.34 \pm 34.15$ & 96.12 \\
\hline
\end{tabular}

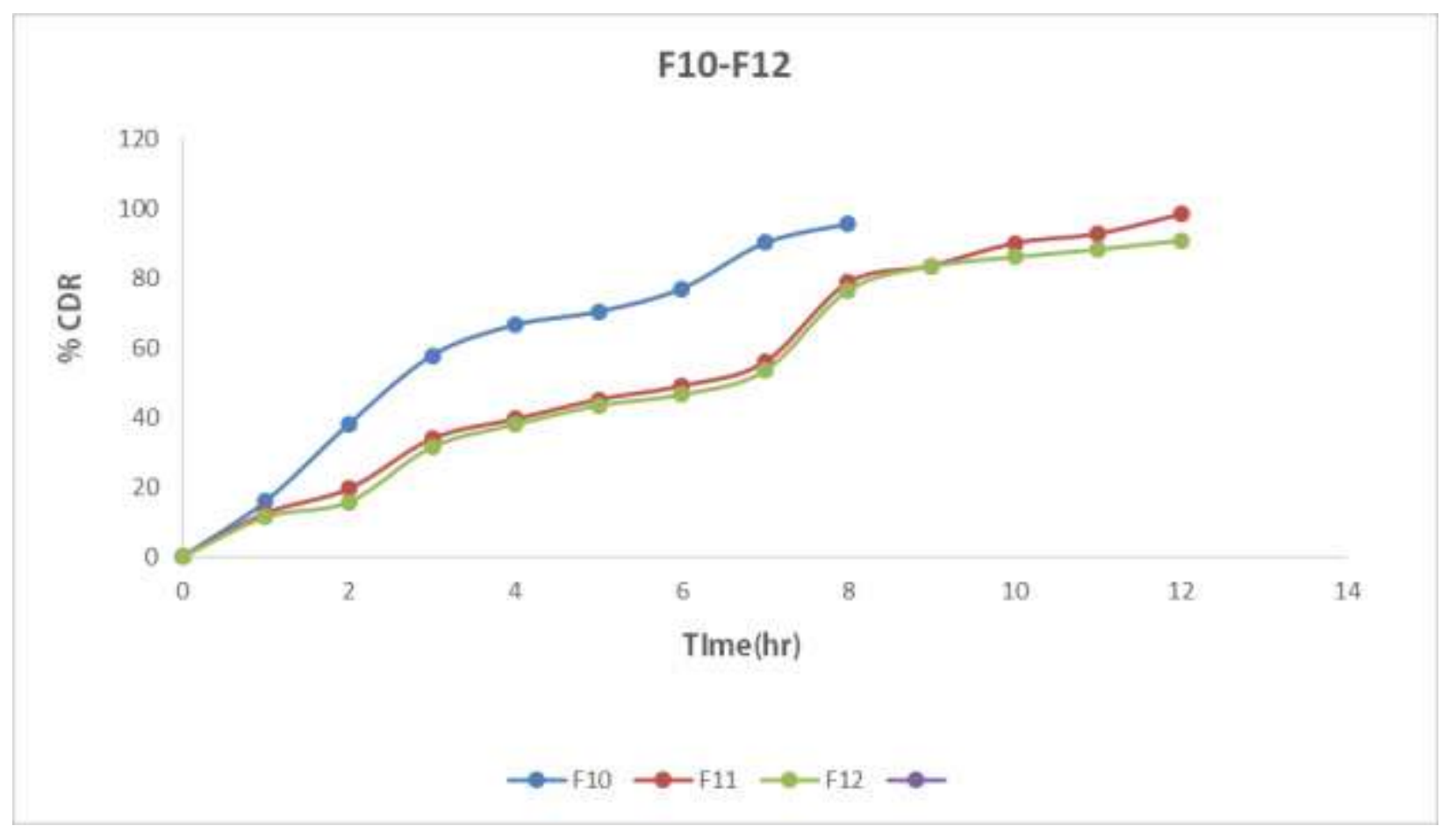

Figure 4: in-vitro drug release study for F10-12 formulation 
Table 5: kinetic modelling data

\begin{tabular}{llllll}
\hline \multicolumn{6}{l}{ Formulation codeZero orderFirst orderHiguchi } \\
K1 & 0.896 & 0.554 & 0.938 & 0.786 & 0.544 \\
F2 & 0.956 & 0.662 & 0.927 & 0.707 & 1.555 \\
F3 & 0.896 & 0.587 & 0.929 & 0.754 & 1.290 \\
F4 & 0.925 & 0.604 & 0.934 & 0.712 & 1.375 \\
F5 & 0.966 & 0.650 & 0.933 & 0.751 & 1.365 \\
F6 & 0.969 & 0.660 & 0.940 & 0.792 & 1.404 \\
F7 & 0.942 & 0.592 & 0.930 & 0.634 & 1.451 \\
F8 & 0.922 & 0.582 & 0.944 & 0.655 & 1.298 \\
F9 & 0.920 & 0.592 & 0.941 & 0.669 & 1.183 \\
F10 & 0.942 & 0.616 & 0.895 & 0.675 & 1.504 \\
F11 & 0.977 & 0.661 & 0.870 & 0.776 & 1.325 \\
F12 & 0.971 & 0.682 & 0.879 & 0.801 & 1.304 \\
\hline
\end{tabular}

Table 6: Physicochemical parameter of formulation F11 during stability studies

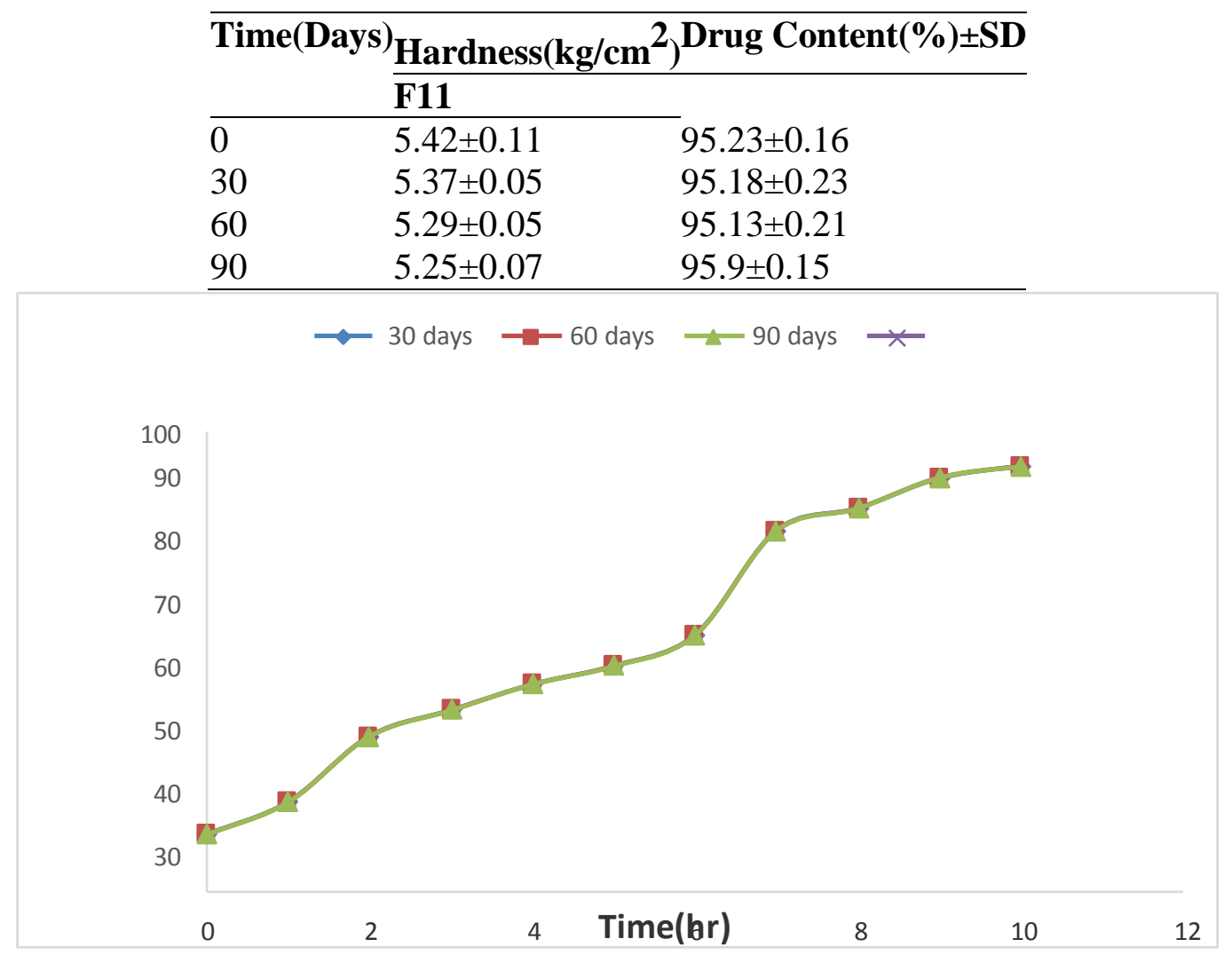

All reading is mean of 3 readings

Figure 6 in-vitro drug release of formulation F11 during stability studies 


\section{Stability studies}

Stability studies was carried for selected formulation F11 at various intervals of 30 days and 90 days and were evaluated for physicochemical parameters. There were no significant differences between initial values and results obtained during stability studies.

\section{CONCLUSION}

Sustained release formulation of Ketoprofen was prepared with different grades of polymer like xanthan, guar gum and chitosan, standard calibration curve was prepared for Ketoprofen in pH 7.4 phosphate buffer and the lambda max was obtained at $260 \mathrm{~nm}$. FTIR spectra of pure drug and drug-polymer mixture revealed no interaction. Total Twelve batches of tablets were prepared using polymers such as guar gum ,xanthan gum chitosan and mixture of guar gum and xanthan gum was used in sustained release layer prepared by direct compression method. Various physicochemical parameters like thickness, hardness, friability, weight variation and $\mathrm{u} \mathrm{n} \mathrm{i} \mathrm{f} \mathrm{o} \mathrm{r} \mathrm{m} \mathrm{i} \mathrm{t}$ of drug content studies were evaluated all the parameters were in the limits prescribed with in the slight deviation of prescribed limit. In vitro dissolution studies were also performed for the drug release study it was concluded F11 was the best formulation. Stability study of F11 formulation showed no major change in physicochemical parameters and drug release profile at $40 \pm 2{ }^{\circ} \mathrm{C} / 75 \pm 5 \% \mathrm{RH}$ after 30 days and 60 days. Thus among all the developed formulations, F11 formulation sustained the drug release for longer period of time over $12 \mathrm{~h}$ when compared to other formulation. So F11 was selected as the best formulation. From the result, guar gum, xanthan gum and chitosan retards the release rate of drug and the tablet made by using polymer can be used as sustained release. thus formulating a matrix tablet dosage form by using different proportion and grades of release rate controlling polymer has been achieved with success.

\section{REFERENCES:}

1. Basak SC, Jayakumar RBM, Lucas MK. Formulation and release behavior of Sustained Release Ambroxol Hydrochloride HPMC Matrix Tablet, Ind. J. Of Pharmaceutical Science 2006;68(5):594-597.

2. Dandagi PM, Mzstiholimat VS, Patilm.B, Manvi FV, Gagad AP, Sharma R, Development And Evaluation Of Theophylline And Salbutamol Sulphate Sustained Release Matrix Tablets, Ind. J. Of Pharm Science 2005;67(5):598-602.

3. Biwal PK, Kumar A, Bhadouriya AS. Design and evolution of colon specific drug system. IJPCBS. 2013;3:1:150-167. 
4. Nutrition and Health Educator, Inc. DBA Nutrigenesis Approach. Accessed July 27,2006.

5. Jain A, Yashwant G, KJ Sanjay, “ Perspectives of biodegradable natural Polysaccharides for site- specific drug delivery to the colon" J pharm pharmaceutics Sci.2007;1:86-128

6. Kumar V, Prajapati SK, Soni GC, Singh M, Kumar M. Sustained release matrix type drug delivery system: A Review world J. of pharmacy and pharm Science 2012; 1(3):934-960.

7. Sayad I, Abdel -Rahman, Gamal MM, EI-Badry Preparation and comparative evaluation of sustained release metoclopramide hydrochloride matrix tablets, Saudi pharma J 2009;17(2):283-288.

8. Chandran S, Laila FA, Mantha N. Design and evaluation of Ethyl cellulose based ,Matrix tablets of ibuprofen with $\mathrm{pH}$ modulated release kinetic. Ind. J. Pharm Sci 2008; 5(70): 592-602.

9. Gothi GD, Parinh BN, Patel TD, Prajapati ST, Patel CN. J of Global Pharma T e c h n olo gy $2010 ; 2(2): 69-74$. 